Article

\title{
Contamination Improvement of Touch Panel and Color Filter Production Processes of Lean Six Sigma
}

\author{
Chia-Nan Wang, Po-Chih Chiu * (D), I-Fang Cheng * and Ying-Fang Huang \\ Department of Industrial Engineering and Management, National Kaohsiung University of Science and \\ Technology, Kaohsiung 80778, Taiwan; cn.wang@nkust.edu.tw (C.-N.W.); winner@nkust.edu.tw (Y.-F.H.) \\ * Correspondence: 2106317121@nkust.edu.tw (P.-C.C.); 1105407101@gm.kuas.edu.tw (I.-F.C.)
}

Received: 25 March 2019; Accepted: 5 May 2019; Published: 8 May 2019

Featured Application: Many companies have experience in lean production and Six Sigma. Lean manufacturing allows companies to know how to reduce waste that should not exist. Six Sigma tells the company what production model it should have. Lean Six Sigma is integrated into the improvement process, shortening the time required for overall improvement and the controversy that can arise when performing two improvement activities separately; the two have complementary effects in application. Much of the literature is mainly devoted to academic discussion of Lean Six Sigma, but this research is primarily directed at the application of industrial practice. Of course, it is not difficult to find a discussion about drug application or public policy in the literature, but this article is mainly used for optoelectronic materials and component manufacturing. It is hoped that more industries will be able to apply the Lean Six Sigma Model to help manufacturing continue to improve in the future.

\begin{abstract}
Color filter (CF) and touch panel (or touch sensor (TS)) are important components for optoelectronic materials and component manufacturing. Due to the cut-throat world of market in the manufacturing, the processes of color filters are similar to touch sensors. The case invested in the production of touch panels in 2009. After a long period of quality improvement, the problem of contamination pollution still accounts for $\sim 30 \%$ of the total variation. In addition to the external problem, there is also the fail of communication caused by dirt or peeling. Therefore, the case was established to improve the dirt defect by setting up Lean Six Sigma project, and the project goal was to reduce the proportion to $0.18 \%$. After three months of improvement and three months of continuous observation, the abnormal proportion of pollution decreased from $0.35 \%$ of the overall average defect loss to $0.13 \%$ (the improvement rate reached $63 \%$ ). It is estimated that the entire product can generate 3 million (USD) of performance for the case in one year. It is also possible to increase the customer's satisfaction and the company's technical competitiveness by improving yield and achieving the continuous improvement of objectives.
\end{abstract}

Keywords: contamination; Lean Six Sigma (LSS); continuous improvement

\section{Introduction}

In recent years, with the rise of optoelectronic materials and components manufacturing in China and competition in the supply chain, the production profit of LCD has been reduced. Many panel manufacturers have increased the production capacity of touch panels to increase production profits and also regulate production capacity. With the rise of smart products, touch panels have increased the willingness of consumers to purchase due to the advantages of portability. However, quality is an important key to touch panels, but the literature about improving the yield of touch panels is still insufficient. Therefore, this study integrates the experience of liquid crystal display production into 
the improvement of the touch panel for many years, and integrates the management model of LSS to increase production capacity and reduce production cost.

The case of this study hopes to promote quality improvement activities by combining lean production of Six Sigma in order to continuously improve organizational operations, reduce resource waste, improve product and service quality, accelerate organizational efficiency, and meet the needs and expectations of interested parties. This study uses the LSS method to establish a production mode that can be controlled by the process in the Six Sigma model and allow for continuous improvement of waste that should not exist in the processes through the lean production system. This study selects the highest proportion of defects in customer return data for improvement. In the customer's return data, the proportion of dirt is the highest.

"Dirt" is a big problem (as Figure 1); although it is only a yield loss data that their customers give back. After simple sampling analysis and confirmation with electron microscope, "dirt" includes all contaminants from the process, such as particles from the air, variations from materials, aging and rusting from equipment, etc.; they look very similar under visual inspection. The type is just a black dot (20-40 micrometers). Therefore, they are all called "dirt" defects. Customer want "dirt" that should be improved.

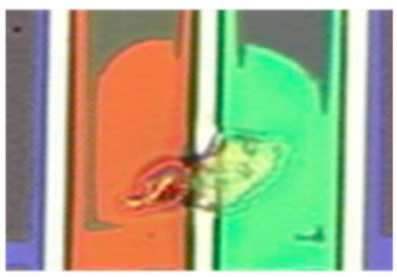

(a)

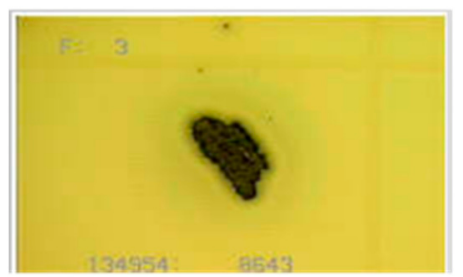

(b)

Figure 1. Photos that are dirt under an electron microscope: (a) color filter and (b) touch sensor.

If this defect is found in the manufacturing processes, this product not only requires laser repair, but may even need to be scrapped. Because the processes need to be stacked it not only needs to be repaired, but scrapped. In addition to causing appearance problems, it can cause problems of signal failure for touch sensors. If inadvertently shipped to the customer, the product may not only need to be exchanged, but also compensated for. Because CF and TS need to be attached to other parts, if the defect is found to be abnormal, these materials must be scrapped together, for example, cover lens and anisotropic conductive films (ACFs), because the disassembly will affect the appearance of the product. So, the case sets up improvement projects to solve this issue.

Many organizations, in order to meet the demands of a competitive market (including competition for quality, cost, delivery, and service), improve the needs and expectations of interested parties. LSS is a combination of Lean Manufacturing and Six Sigma. The first concept of LSS was created in 2001 by a book "Leaning into Six Sigma: The Path to Integration of Lean Enterprise and Six Sigma" [1]. A follow-up study by George and Furterer also related this book to LSS [2,3]. As Wheal said, Lean and Six Sigma are useful for any process in the organization, not just manufacturing. To be an LSS company, managers must address all processes, from the factory floor to customer service. Lean establishes the standard. Six Sigma removes the deviations from that standard [4]. This is also because of the past lean production and Six Sigma management in the 20th century in the corporate management [5]. In addition to Toyota, Motorola, and GE, many other Fortune 500 companies have already implemented Lean production and Six Sigma [6].

Lean production or lean manufacturing is usually referred to as "lean". Among the several quality management concepts that have been developed, the lean concept is one of the more widespread and successful attempts. Lean is derived from the Japanese manufacturing industry. The term was first coined by Krafcik, based on his Master's thesis at the MIT Sloan School of Management. Krafcik was a quality engineer in the Toyota-GM NUMMI joint venture in California before joining MIT for MBA studies. Krafcik's research was continued by the International Motor Vehicle Program (IMVP) at 
MIT, which produced the international best-selling book coauthored by James. A complete historical account of the IMVP and how the term "lean" was coined is given by Holweg [7].

Six Sigma $(6 \sigma)$ is a set of techniques and tools for process improvement. Six Sigma is a registered service mark and trademark of Motorola Inc. In 2005, Motorola attributed over US\$17 billion in savings to Six Sigma. Other early adopters of Six Sigma include Honeywell and General Electric (GE), where Jack Welch introduced the method. By the late 1990s, approximately two-thirds of Fortune 500 organizations had begun Six Sigma initiatives with the aim of reducing costs and improving quality. The Six Sigma method has two methods of implementation. These methodologies, composed of five phases each, bear the acronyms DMAIC (Define, Measure, Analysis, Improve, Control) [8].

Womack mentioned the use of confirming value to implement a sophisticated systemic approach to eliminating waste. The approach has five principles (Define Value, Value Stream Mapping (VSM), Flow, Pull, and Perfection) [9]. LSS not only reduces process defects and waste, but also provides a framework for overall organizational culture change. LSS isn't only appropriate for a factory, but also for all process such as sales and marketing, order processing, product development, etc.; these must also be improved in the companies since they enable the process; as a matter a fact, companies are recognizing that there is a remarkable value-creating opportunity in engaging these processes because they have been neglected in the past [10].

The rest of the document is organized as follows. Section 2 offers the related application literature on the LSS in order to learn how LSS can improve activities in the project through the relevant literature. Section 3 describes the case study, context of the research, and methodology applied. Conduct this improvement project plan. Section 4 presents the results that were obtained once the methodology was applied. Finally, Section 5 contains the conclusions and recommendations derived from the case study.

\section{Research Design}

If the amount of contamination in the process exceeds the standard value, it is necessary to carry out the cleaning of the entire production machine and affect the production of the product. The methodology used was based on the process proposed by Wedgwood for project improvement [11] (pages 65-67), including (a) a literature review from similar published articles and case studies using LSS; (b) definitions based on the DMAIC phase; (c) application of measurement system analysis (MSA), the design of experiment (DOE), statistical process control (SPC), failure modes, and effect analysis (FMEA) are equivalent to improving the tools and techniques used in the project; (d) analysis of results; and finally (e) conclusions and recommendations.

Chen [12] hopes to reduce the panel's failure rate and cost by effectively improving the quality and productivity of TFT-LCD panels. The TFT-LCD panel manufacturing process was discussed in Chen's study and then five key quality features (critical to quality (CTQ)) were identified. Six Sigma of the Process Quality Index (Cpm) evaluation model and the MAIC (Measurement-Analysis-Improvement-Control) method were used at the beginning of the project to measure and analyze panel failure characteristics. In the later stages of the project, Hartley's uniformity testing and joint confidence intervals were performed to determine the optimal parameter settings for key factors in the TFT-LCD panel manufacturing process. Six Sigma quality levels can be achieved by using these optimal settings. Chen [13] describes a procedure that applies Six Sigma approach to enhance quality in touch sensor manufacturing.

Caligiana proposed to integrate QFD (quality function deployment) and TRIZ (Teoriya Resheniya Izobreatatelskikh Zadatch) to reduce production time and waste of resources [14]. Frizirio and Francia used QFD combined with TRIZ to improve quality, providing an innovative design approach through the integration of QFD and TRIZ $[15,16]$. Through these three researches, we can understand that TRIZ and QFD can be one of the important tools of LSS.

Takatsuji [17] used Taguchi methods and found that pinholes in the aluminum thin film are strongly related to the sputtering parameters, and that pinhole density is related to the surface roughness of the Al thin film. Chiang [18] used Taguchi methods; it was used to find process parameters with quality characteristics. The weight of the quality characteristics was determined by using the measurement 
method, and two quality characteristics and four control factors were selected. Based on the design concept of Taguchi method, the L9 orthogonal array table was selected for the experiment. Confirmation of the experimental verification based on the Taguchi experimental method can find the optimal process parameters with multiple quality characteristics. In addition, production processes that achieve optimal process parameters reduce process repair and rework opportunities and increase throughput.

By using statistical process control (SPC) technology, it is possible to assess the effectiveness of older production lines and extend their production capacity at minimal cost, as shown in Zheng's study [19]. In the study of Kornfeld [20], he fills a gap in the literature by providing researchers and practitioners with an overview of approaches, a better understanding of the shortcomings of current approaches, and a normative model that highlights areas for further research. Cima [21] applies Lean Sigma to medical systems to improve the efficiency and performance of the operating room (OR). Dahlgaard's research analyzes the history of Lean Manufacturing, Six Sigma, and Total Quality Management (TQM), and understands the resources companies need to invest in these continuous improvement activities [22]. Realyvásquez-Vargas reduced the number of defective components in an electronics factory in Mexico through a lean production system and incorporating the concept of a quality-adjusted PDCA (Plan-Do-Check-Action) [23].

\section{Research Methodology}

This study conducted a practical case study with LSS. The research methods discussed in this section and in the previous chapters with an actual improvement process of the case. Since this situation is mainly used for processes improvement, this section defines the research steps for each stage in the DMAIC phase.

\subsection{D (Define) Phase}

1. The case study mainly produces color filters and touch sensors. In the processes, because the proportion of contamination is too high, affecting internal processes production, the number of rejects is too high. It even affects production schedules, equipment utilization, and product turnover. Therefore, the company set up an improvement project to solve this problem: the first phase of the project. Basically it involves defining the problem, the input/output, and the process factors. This consists of four steps: first is checking the problem statement, then current situation. Finding out what the customer really wants to improve about the problem, defining the quality specifications, and finding which characteristics the product needs to have in order to satisfy the customer. Next, we check the process map with a Supplier-Input-Process-Output-Customer (SIPOC) diagram. Finally, we set-up a project team. Table 1 shows the project's steps, description, indicators, and tools. In this phase, the most important thing is to clarify the needs of internal and external customers and clearly define the project objectives. In this case, a project team was set up with a black belt as the project leader and six green belts as project members, and the members' respective rights and responsibilities were defined in this phase: The project team can preconfirm the workflow and plan using the SIPOC diagram.

2. Confirm the cause of the defect with the fishbone diagram.

3. Confirm the rate of defect with Pareto as the basis for the improve assessment.

4. Accounting unit evaluates the financial performance of the project through cost profit analysis.

5. Confirm internal and external customer needs to set the project's goals through benchmark analysis.

The output in this phase mainly includes project planning in the Measure phase, input/output factors for the project monitoring, and the most important project objectives. If the benchmark analysis is carried out and the performance of the project is not effective for the organization, it may be decided in this phase to stop the project and avoid the waste of resources. The final decision is still made by the organization. This will also consider the future development of the organization's sustainability. If the project is confirmed, the leadership's support and rigorous training are the main reasons for 
the success of the project. Although it may be in the entire project, it will not directly link with the performance of the project. This is very important in the literature and in case studies.

Table 1. Define phase: steps, description, indicators, and tools.

\begin{tabular}{|c|c|c|c|}
\hline Steps & Description & Indicators (Outputs) & Tools \\
\hline $\begin{array}{l}\text { 1. Problem statement } \\
\text { 2. Current situation } \\
\text { 3. Process map-As-is } \\
\text { SIPOC } \\
\text { 4. Set up a project team }\end{array}$ & $\begin{array}{l}\text { We divide our customers } \\
\text { and classify this one's } \\
\text { using data as the market } \\
\text { share or the loyalty } \\
\text { index, knowing which } \\
\text { ones are the most } \\
\text { important for us. After } \\
\text { knowing our main } \\
\text { customers, we } \\
\text { understood what their } \\
\text { expectations. }\end{array}$ & $\begin{array}{l}\text { 1. Project evaluation plan } \\
\text { 2. Project team members' } \\
\text { powers and } \\
\text { responsibilities } \\
\text { allocation table } \\
\text { 3. Process definition flow } \\
\text { chart and key process } \\
\text { indicators }\end{array}$ & $\begin{array}{l}\text { 1. SIPOC } \\
\text { 2. Pareto Diagram } \\
\text { 3. Fishbone diagram } \\
\text { 4. Cost Profit Analysis } \\
\text { 5. Benchmark analysis }\end{array}$ \\
\hline
\end{tabular}

\section{2. $M$ (Measure) Phase}

LSS builds a complete framework and process for problem solving. Table 2 shows the steps undertaken in the Measure phase. Streamlined manufacturing reduces inventory levels throughout the supply chain and reduces waste. When the production flow chart is confirmed, the lean production system can be combined to improve the production process, reduce waste, and reduce unnecessary movements in the process through value engineering. Therefore, the measurement phase continues the definition phase for processes optimization. After confirming the processes, it is necessary to confirm whether the measurement system has doubts on the measurement of the project indicators before the Analysis and Improve phase. After confirming that there is no doubt, it is necessary to reconfirm the processes capability of the product and whether it conflicts with the previously collected information. This consists of five steps, starting with the continuation of the definition phase to confirm whether the project definition needs to be changed. The second is to reconfirm the key input and output factors of the project and how these factors are measured. After confirming that there are no problems regarding the measurement, we confirm the current process capability (such as FTY or Cpk). Finally, the indicators are used to reconfirm the performance that the project can bring to the organization. We used the tools outlined earlier to achieve the following.

1. Combine the value engineering to confirm the current operation process, distinguish it into valuable, worthless, incidental actions, and reduce the eight wastes in the process to reconfirm the process flow diagram.

2. Analyze and produce the Quality Function Deployment (QFD) in combination with product production requirements.

3. The case has been electronically in the original production system, followed by the combination of lean manufacturing application-related tools, including kanban, to speed up production communication.

4. $5 \mathrm{~S}$ is a way to create and maintain an organized, clean, and secure high-performance work environment that continues to promote the organization of on-site workers to carry out $5 S$ training and lets personnel develop good work habits.

5. Through the above-mentioned process monitoring indicators, the difference of the measurement system is analyzed if the measurement error exceeds $10 \%$, and the improvement should be evaluated. If it exceeds $30 \%$, the update measurement method needs to be evaluated.

The output in this phase mainly includes the confirmation of the production processes and monitoring indicators, including input and output indicators and measurement system analysis, to avoid excessive measurement error affecting production monitoring. At this time, it is necessary to make good use of statistical tools to analyze the sources of variation in the measurement process. 
These will be the main key points for continuous improvement. After confirming that there is no problem with the measurement, we reconfirmed the current process capability. Of course, there is also an opportunity to find out that the issue mainly comes from misjudgment after reconfirming the measurement method. After re-establishing the measurement system, the case can be closed.

Table 2. Measure Phase: Steps, Description, Indicators, and Tools.

\begin{tabular}{|c|c|c|c|}
\hline Steps & Description & Indicators (Outputs) & Tools \\
\hline $\begin{array}{l}\text { 1. Clear project } \\
\text { definition } \\
\text { 2. Identification of input } \\
\text { and output indicators } \\
\text { 3. Analysis measurement } \\
\text { system } \\
\text { 4. Identify the process } \\
\text { capability of the product } \\
\text { 5. Defining project } \\
\text { performance and } \\
\text { objectives }\end{array}$ & $\begin{array}{l}\text { Through the flow chart } \\
\text { to identify the definition } \\
\text { of the project and } \\
\text { calculate the mobile } \\
\text { output rate of the project } \\
\text { (RTY), Lean } \\
\text { manufacturing is applied } \\
\text { to eliminate waste and } \\
\text { improve the process; } \\
\text { after the MSA is } \\
\text { identified, the current } \\
\text { manufacturing process } \\
\text { capability is identified } \\
\text { again. }\end{array}$ & $\begin{array}{l}\text { 1. FTY (First Time Yield), } \\
\text { IPY (In Process Yield), } \\
\text { RTY (Rolled Throughput } \\
\text { Yield) } \\
\text { 2. MSA: \%R\&R, NDC } \\
\text { 3. Cpk, Ppk, DPU }\end{array}$ & $\begin{array}{l}\text { 1. Process Flow Diagram, } \\
\text { PFD } \\
\text { 2. Quality Function } \\
\text { Deployment, QFD } \\
\text { 3. Lean, Pull System } \\
\text { 4. 5S (Sorting, Storage, } \\
\text { Shining, Standardize, } \\
\text { Sustaining) } \\
\text { 5. Analysis of basic } \\
\text { statistical ability and } \\
\text { process capability }\end{array}$ \\
\hline
\end{tabular}

\subsection{A (Analysis) Phase}

Table 3 shows the work tasks that should be performed during the analysis phase. Once we understand the customer's needs and have collected the data (measurement phase), we must emphasize the main issues for improvement planning. This situation continues as teams analyze data and processes to reduce and verify the root causes of waste and defects. The factors that cause problems in most problems are difficult to determine. Therefore, in the analysis phase, this study suggests using graphical analysis methods to determine the possible causes of various process variations. Factor selection is performed by the experimental design methods. At this time, screening DOE or Taguchi methods can be used to achieve the mission objectives of this phase. It is hoped that the experimental results will show sufficient importance and data repeatability in the final analysis. We used the aforementioned tools to achieve the following.

1. The key to successful use of DOE in Lean Sigma is to have good planning and to keep the application practically based. First, through the observation of the process, we first confirm the cause of the experiment.

2. DOE is not just a single tool, and in fact, it is best not to conduct a single experiment to understand a process. The best approach is to use what is known as sequential experimentation. Simple experiments are conducted first, and once completed the information they generate is used to plan the next experiment.

3. The case is expected to perform the DOE-screening design and DOE-optimized design.

4. After the experimental data is obtained, with the application of the graphic analysis method and the statistical software, the results of the experiment are analyzed for the production planning. 
Table 3. Analysis Phase: Steps, Description, Indicators, and Tools.

\begin{tabular}{|c|c|c|c|}
\hline Steps & Description & Indicators (Outputs) & Tools \\
\hline $\begin{array}{l}\text { 1. Identify the source of } \\
\text { variation } \\
\text { 2. Screening test design } \\
\text { 3. Perform analysis after } \\
\text { performing screening } \\
\text { test } \\
\text { 4. Confirm test results } \\
\text { and process variation } \\
\text { 5. Reconfirm the } \\
\text { production conditions of } \\
\text { the product }\end{array}$ & $\begin{array}{l}\text { The information } \\
\text { collected during the } \\
\text { Measure phase will be } \\
\text { confirmed by the } \\
\text { expenimental design } \\
\text { method for the variation } \\
\text { reasons that may affect } \\
\text { the project results. After } \\
\text { confirming the } \\
\text { conditions affecting the } \\
\text { variation, re-analyze to } \\
\text { confirm the mass } \\
\text { production test of the } \\
\text { subsequent } \\
\text { improvement phase of } \\
\text { the improved production } \\
\text { conditions. }\end{array}$ & $\begin{array}{l}\text { Decide on the } x \text { factor } \\
\text { that affects the Y-value. }\end{array}$ & $\begin{array}{l}\text { 1. Graphic analysis } \\
\text { methods: including } \\
\text { scatter diagrams, matrix } \\
\text { plots ... } \\
\text { 2. Statical method: } \\
\text { including regression } \\
\text { analysis, DOE - } \\
\text { Screening ... }\end{array}$ \\
\hline
\end{tabular}

All rash changes will have an impact on the process. Therefore, the experiments to be carried out in the analysis phase must be strictly controlled and need to require the Production Change Notice (PCN). During the experiment, both the equipment and the product have clear indications to avoid the quality of the product caused by the mixture. The main desired output at this phase is to evaluate the optimization process possibilities through statistical methods. However, even if the results of the experiment are obtained, it is recommended not to directly introduce production conditions. It is still necessary to carry out testing in the next phase to confirm that it will not adversely affect product.

\subsection{I (Improve) Phase}

Refer to Table 4 for the steps, indicators, and tools in the Improve phase. Through the experiments in the analysis phase, improved production conditions can be obtained. However, if you do not verify, importing directly into mass production conditions may increase the risk of the processes. Therefore, in the improve phase and before introducing production conditions, it is necessary to open a Process Change Request (PCR) to arrange the verification test. After confirming, import the mass production. If during the test other production concerns are found, there exists the need to assist the relevant units to eliminate issue problems. This can increase the stability of process control. After verifying the production conditions, it is still necessary to continuously observe the change of the process in the Control phase to avoid other factors interfering with the expected improvement effect. During the verification period, the project team needs to record changes in the production process and complete the verification report. When the follow-up project is handed over, the relevant technical data will be transferred to the responsible unit. In future, let the powers and units use these technical materials to further control the changes in the process. We used the aforementioned tools to achieve the following.

1. After a large number of statistical tools are used for analysis and the effects of each analysis factor are evaluated, the production conditions for the change required for mass production are confirmed.

2. Strict continuous monitoring is required after the change is implemented. At this time, the control chart is a very good tool.

In the Improve phase, the complete production control factors may not be found after the analysis. It may return to the Measure phase to confirm if any factors have been omitted and not analyzed. When confirming that changes can improve project objectives and introduce mass production, the project team still needs to pay attention to the variation of the processes. The team needs to solve the problems 
caused by the changes. This is related to whether the Improve can continue. In summary, the main output of the Improve phase is the feasibility of mass production to confirm production conditions. If it is confirmed that it can be mass-produced, it is still necessary to continuously monitor whether the process has other changes. The project team transfers the knowledge gained during the project and evaluates the possibility of failures through design changes. This will be the next phase of the mission.

Table 4. Improve Phase: Steps, Description, Indicators and Tools.

\begin{tabular}{|c|c|c|c|}
\hline Steps & Description & Indicators (Outputs) & Tools \\
\hline $\begin{array}{l}\text { 1. Plan for improved } \\
\text { production conditions } \\
\text { and test production in } \\
\text { mass production } \\
\text { 2. Collect relevant } \\
\text { information about the } \\
\text { production procee } \\
\text { 3. Confirm whether the } \\
\text { production process is } \\
\text { derived from other } \\
\text { process issues } \\
\text { 4. Improt formal mass } \\
\text { production }\end{array}$ & $\begin{array}{l}\text { The improvement } \\
\text { conditions obtained } \\
\text { during the improve } \\
\text { phase may be introduced } \\
\text { into mass production, } \\
\text { which may cause } \\
\text { derivative problems. } \\
\text { Therefore, it is necessary } \\
\text { to arrange mass } \\
\text { production trial, and } \\
\text { then import the mass } \\
\text { production conditions } \\
\text { after confirmation. If } \\
\text { there are any problems, } \\
\text { you can also adjust } \\
\text { before improving, which } \\
\text { will increase the stability } \\
\text { of the process. }\end{array}$ & $\begin{array}{l}\text { 1. Process Change } \\
\text { Request (PCR) } \\
\text { 2. Closing Report }\end{array}$ & $\begin{array}{l}\text { 1. Statistical tools: } \\
\text { ANOVA analysis, Effect } \\
\text { Plot } \\
\text { 2. SPC: Control chart }\end{array}$ \\
\hline
\end{tabular}

Incidentally, the difficult statistical techniques are often the reason for the stagnation of Six Sigma. This includes not understanding the results of the analysis or not knowing how to improve after getting the results. These factors can solve this problem by organizing daily education and training. The content of the training is not only the techniques of these statistics, but also the experience of these projects. These are invaluable knowledge for any organization. Therefore, it is also recommended that the organization continue to promote these educational and training activities.

\subsection{C (Control) Phase}

Table 5 shows the steps required in the control phase, the collected indicators, and the tools used. After confirming the improvement, long-term monitoring can be continued through the control chart to confirm whether the production is achieved as expected. If stability cannot be maintained, it must be returned to the analyze phase for confirmation. Finally, confirm the project performance; suggestions are then transferred the relevant technical data in order complete the modification of the program documents (include Control Plan, SIP/SOP, check list, record, etc.). If possible, it is recommended that the R\&D incorporate the improvement method into the processes design (with the Poka Yoke method). The team can then transfer at the end of the project, and in future can be used as the follow-up improvement direction of the enterprise together with the technical know-how to be submitted to the completion report. Once completed, the project team can be decomposed to allow the project members to return to the original unit. We used the aforementioned tools to achieve the following.

1. Through the analysis of each stage, more information can be acquired regarding the failure analysis. This is not only valuable knowledge for the project team, but for the company as well. This is because it is recommended to include this information in the Technical Data - Failure Mode and Effects Analysis (FMEA). 
2. In addition to controlling the output indicators through Control Chart, the assessment incorporates the important input indicators learned during the analysis and improvement phases into the control chart. Reduce the production of fail products to reduce the cost of failure.

3. Poka Yoke hopes to completely avoid failures. But if it can't be achieved; the generalized Poka Yoke can also accept the possibility of reducing the failure. This is also helpful for manufacturing.

4. Examine current manufacturing, incorporate the knowledge gained from the project, and revise the control plan.

5. Based on the regulatory plan, it is rolled out to all standardized documents, including the Standard Inspection Program (SIP), Standard Operating Procedures (SOP), and Checklists for regular inspections.

Table 5. Control Phase: Steps, Description, Indicators, and Tools.

\begin{tabular}{|c|c|c|c|}
\hline Steps & Description & Indicators (Outputs) & Tools \\
\hline $\begin{array}{l}\text { 1. Continuous } \\
\text { observation of the } \\
\text { changed production } \\
\text { system } \\
\text { 2. Collect production } \\
\text { data } \\
\text { 3. Confirm whether } \\
\text { performance has } \\
\text { achieved target } \\
\text { 4. Modify relevant SOP } \\
\text { and transfer technical } \\
\text { information } \\
\text { 5. End the project and } \\
\text { return the members to } \\
\text { the original unit }\end{array}$ & $\begin{array}{l}\text { The control phase primarily } \\
\text { seeks to confirm improved } \\
\text { performance through long-term } \\
\text { monitoring. If the performance } \\
\text { is confirmed to achieve the goal. } \\
\text { The project team should } \\
\text { recorganize the project technical } \\
\text { data to produce a closed report } \\
\text { for the project transfer. After the } \\
\text { handover is completed, } \\
\text { members of the project team can } \\
\text { return to the organization's } \\
\text { original preparation to end the } \\
\text { project task. }\end{array}$ & $\begin{array}{l}\text { Closing report: } \\
\text { 1. Assess improved } \\
\text { performance } \\
\text { 2. Related technical } \\
\text { information } \\
\text { 3. Future improvement } \\
\text { suggestions }\end{array}$ & $\begin{array}{l}\text { 1. FMEA } \\
\text { 2. Control Chart } \\
\text { 3. Poka-Yoke } \\
\text { 4. Control Plan } \\
\text { 5. SIP/SOP } \\
\text { 6. Check list }\end{array}$ \\
\hline
\end{tabular}

The team will review the results of the project implementation. Sometimes it is not possible to achieve improvement goals at a certain time, and the project team can be divided into several times to meet the target. This is related to the goal management at the beginning of the definition phase. If it is a well-experienced project team, it may not have much impact on the success of the project. However, an inexperienced project team needs the experience of a successful project to increase confidence in driving the project. This matter has nothing to do with technical ability, but it will have an impact on the organization to promote continuous improvement. Therefore it is recommended that a team that just started the project slowly accumulate successful experience. This is the best education training.

\section{Case Study}

The case is a raw material factory for the panel industry in Taiwan. The case specializes in the manufacturing of CF \& TS. The company was established in 1999. Since 2008, the production of TS has increased from the original production of CF. The number of employees is $\sim 400$. its capital is $\sim 200$ million US dollars. TS products are based on projective capacitive technology. For the description of the CF \& TS process flow, see Figures 2 and 3.

Figure 2 is the color filter product process for the case. Starting from the glass, there are black matrix, red (R), green $(G)$, and blue (B) subpixel production processes. These processes are all part of the photoprocess. Subsequent ITO (indium tin oxide) sputtering. Therefore, the main production is in the photoprocess. The production process of the photoprocess is shown on the right, including cleaning (UV, precleaner), coating, pre-oven \& cooling (HP/CP), exposure (Aligner), develop, and Oven. The last process is the ITO process. Some products will add a photospacer process, which is a photoprocess too. Therefore, this study will improve the photoprocess area. In the center of the Figure 2, a schematic diagram of the product stack structure is shown. 


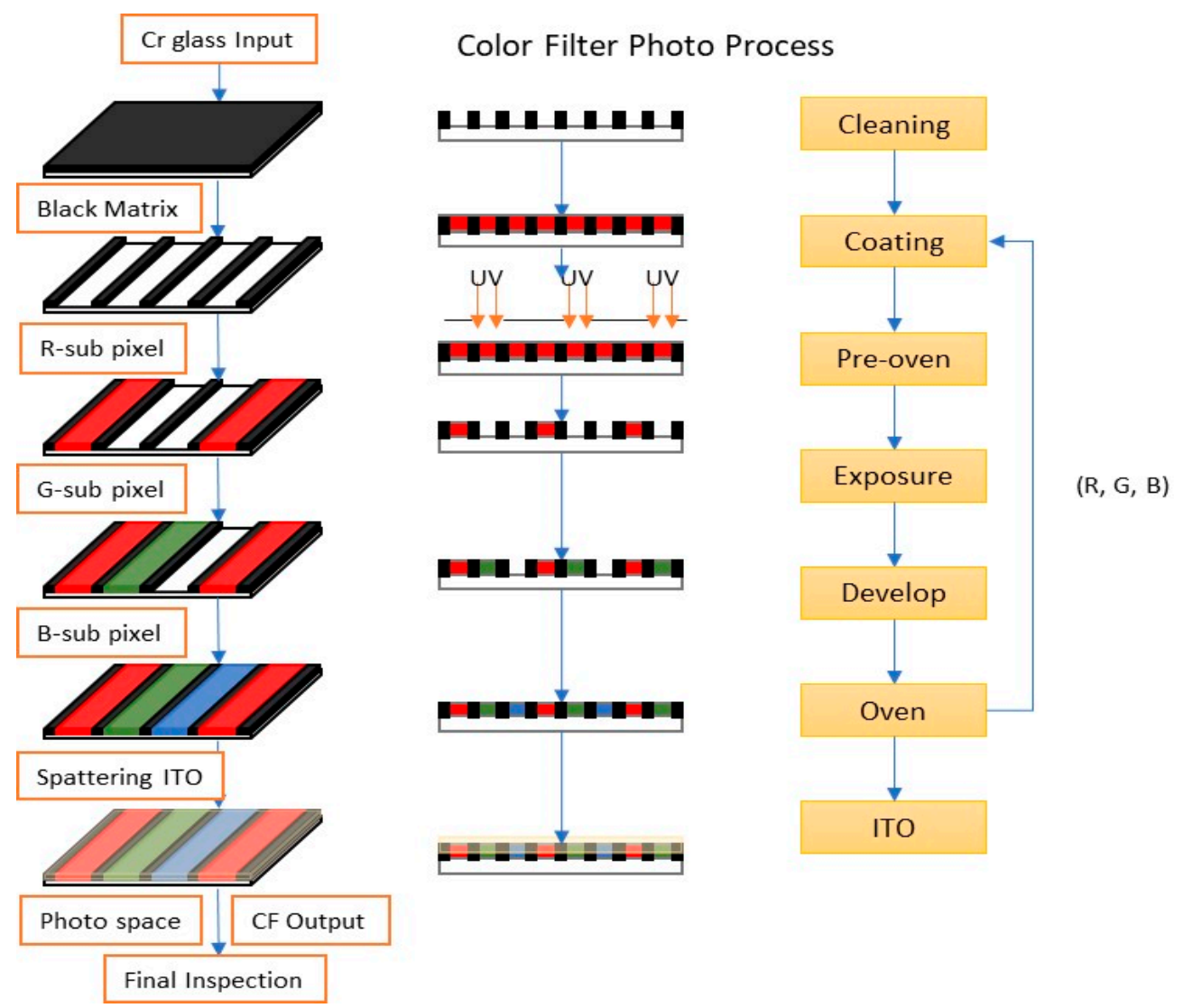

Figure 2. Color filter $(\mathrm{CF})$ processes.
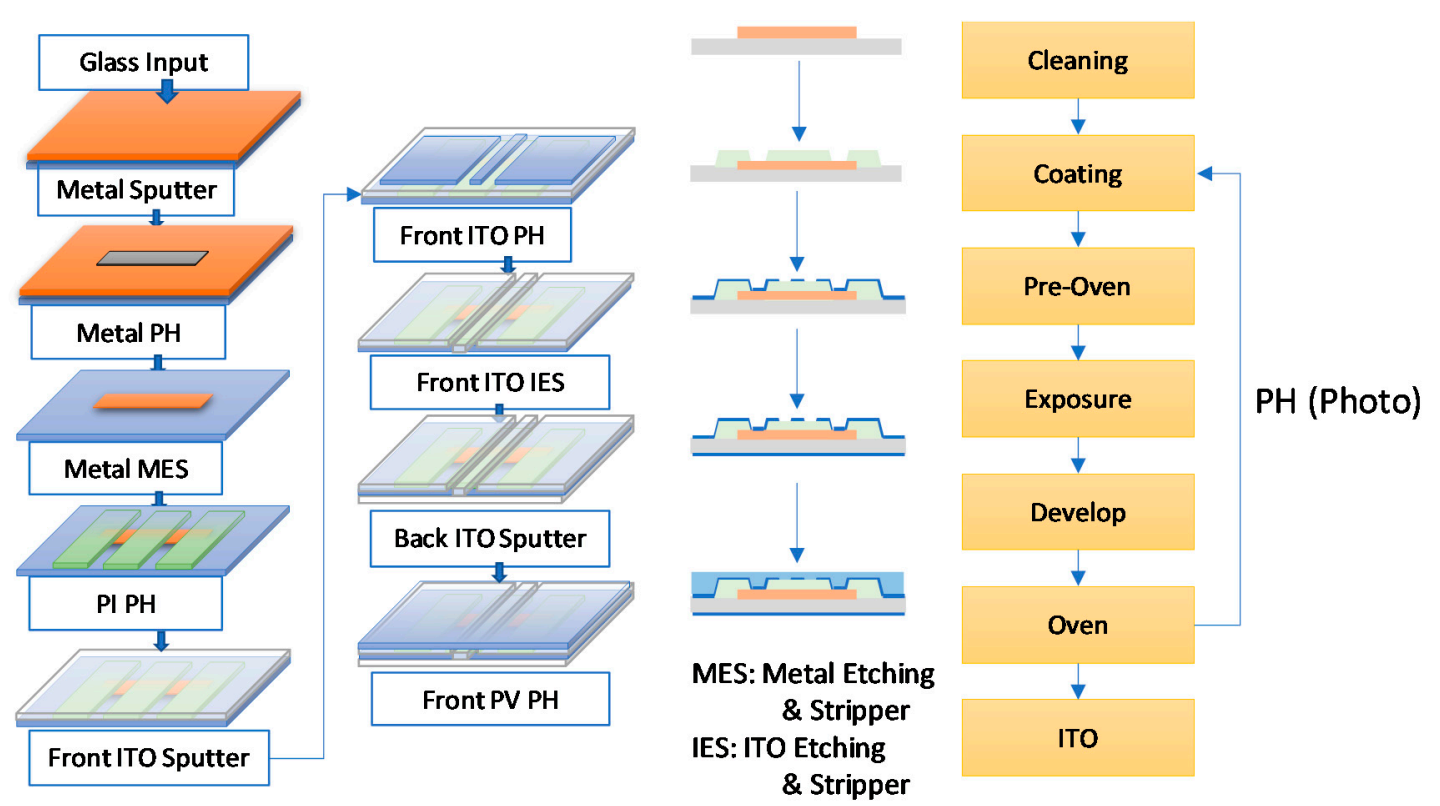

Figure 3. Touch sensor (TS) processes (Source from the case-S company).

Figure 3 is the TS product process for the case. In addition to Metal Sputter and front/back ITO sputter, the process is almost entirely in the photoprocess area. Through the contamination of the touch sensor, the main proportion is also from the photoprocess. The figure on the lower right is a schematic diagram of the stack structure of the TS product.

The case promotes quality improvement projects through Six Sigma. It is important to monitor processes factors in manufacturing, e.g., the flow of purified water in the cleaning equipment and 
temperature changes in baking equipment. The results of the product appearance inspection failure and the related failure data are monitored by the manufacturing measurements, as well as the product characteristic measurements obtained by the monitoring equipment; the risk production batch size of the failure process is reduced.

\subsection{Define Phase}

The main issue of the case is dirt defect. The rate of bad appearance in the product is expressed by $\mathrm{Y}$ and the failure rate of dirt is indicated by y (e.g., photo resistor residue). After issue analysis, the main unusual processes include photo and etching processes (through the analysis of dirt components). Taking as an example CF, the case's H customer returns issue analysis every two weeks one year before the establishment of the case company. The defect loss in the R Layer is as follows; the average loss is $0.35 \%$ and the best loss is $0.11 \%$. The project goal is that the average loss and best level gap $(0.24 \%)$ are reduced by $70 \%$.

The problem of defect is not only a problem of customer return. It is also possible that the defect in the process is too high to repair, which indirectly increases the production cost and affects the manufacturing. One month before the project was set-up, the proportion of other customers who listed dirt in the analysis of issue returns of color filters reached $0.30 \%$. The estimated loss for the whole year was $\$ 0.4$ million USD. The proportion to be refurbished by repair for the whole year is estimated to be 22,000 pieces per year. For $\mathrm{H}$ customers, customers want to reduce the proportion of defect residue to less than $0.2 \%$, so that the loss of all good products can be reduced to $1 \%$ (Customer notification). When the defect's size exceeds $30 \mu \mathrm{m}$ or the height exceeds $3 \mu \mathrm{m}$ in the micro-inspection or is invisible in the macro-inspection. If it was inspected and found, it will be judged as a failure of product.

The processes definition can be described in Figure 4. The team will confirm the process flow and evaluate the Key Process Output Variables (KPOVs) for this improvement (e.g., poor environment, photo resistor left, the fail of coating (e.g., back dip, pipeline bubble, and time setting), cleanliness, detection, and misjudgment) and the Key Process Input Variables (KPIVs). These input/output items will be integrated during the Measure phase.

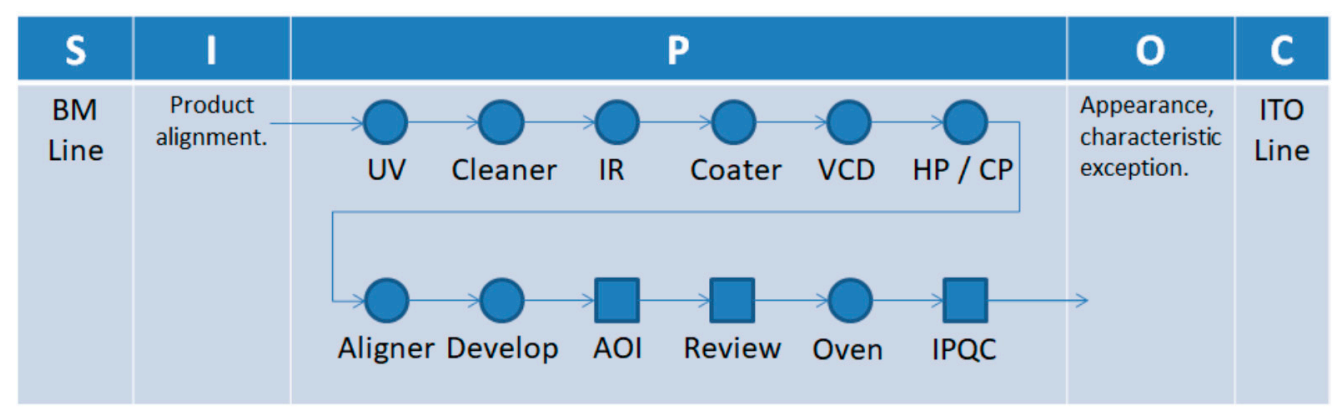

Figure 4. The Supplier-Input-Process-Output-Customer (SIPOC) diagram of issue case's processes.

The project team identified the process and began gathering information on the site. Based on the information, we can define which conditions are controlled by the field personnel and their differences (labeled C), or which process noise cannot be controlled on the spot (labeled N). These annotations will help clarify the key input/output factors.

The project was internally evaluated by the organization, and the improvement was in line with customer expectations. If the project can achieve the improvement goal, the benefits created in one year will be estimated to be $\$ 0.27$ million after deducting the cost. So we confirmed the establishment of an improved project.

\subsection{Measure Phase}

During the Define Phase, the key inputs and outputs (KPIVs \& KPOVs) for defining the project have been completed. At the beginning of Measure phase, the team completes the C\&E (Cause and 
Effect) matrix, such as Table 6 and converts it to a Pareto chart, as shown in Figure 5, in which the coating parameters, photo resistor characteristics, and action analysis of operators are included. These are the main factors that influence the production variation. The determination of the cause of these failures is mainly through the component analysis of the defective samples, the observation of the on-site personnel operation, and the statistical analysis by the integrated department. Before the follow-up Analyze Phase, the project team asked the field staff to collect the actual production data to facilitate the process capability analysis.

Table 6. C\&E matrix for dirt defect analysis.

\begin{tabular}{ccccccc}
\hline \multicolumn{1}{c}{ Importance Degree } & $\mathbf{1}$ & $\mathbf{3}$ & $\mathbf{8}$ & $\mathbf{9}$ & $\mathbf{9}$ \\
\hline \multicolumn{1}{c}{ KPOVs } & $\begin{array}{c}\text { Poor Production } \\
\text { EPIVs }\end{array}$ & $\begin{array}{c}\text { Poor } \\
\text { Cleanliness }\end{array}$ & $\begin{array}{c}\text { Fluid } \\
\text { Instability }\end{array}$ & $\begin{array}{c}\text { Nozzle } \\
\text { Sticked }\end{array}$ & $\begin{array}{c}\text { Photo Resist } \\
\text { Stripping }\end{array}$ & $\begin{array}{c}\text { Total } \\
\text { Coating parameters }\end{array}$ \\
Photo resist characteristic & 1 & 1 & 1 & 9 & 9 & 174 \\
Operating process & 1 & 1 & 3 & 3 & 9 & 136 \\
Coater material anomaly & 1 & 1 & 3 & 9 & 1 & 118 \\
The arm of Robot dust & 1 & 1 & 9 & 3 & 1 & 112 \\
CV dust & 1 & 9 & 1 & 1 & 1 & 54 \\
VCD dust & 1 & 9 & 1 & 1 & 1 & 54 \\
HEPA leakage & 9 & 1 & 1 & 1 & 1 & 54 \\
HP sublimation & 1 & 1 & 1 & 1 & 1 & 38 \\
\hline
\end{tabular}

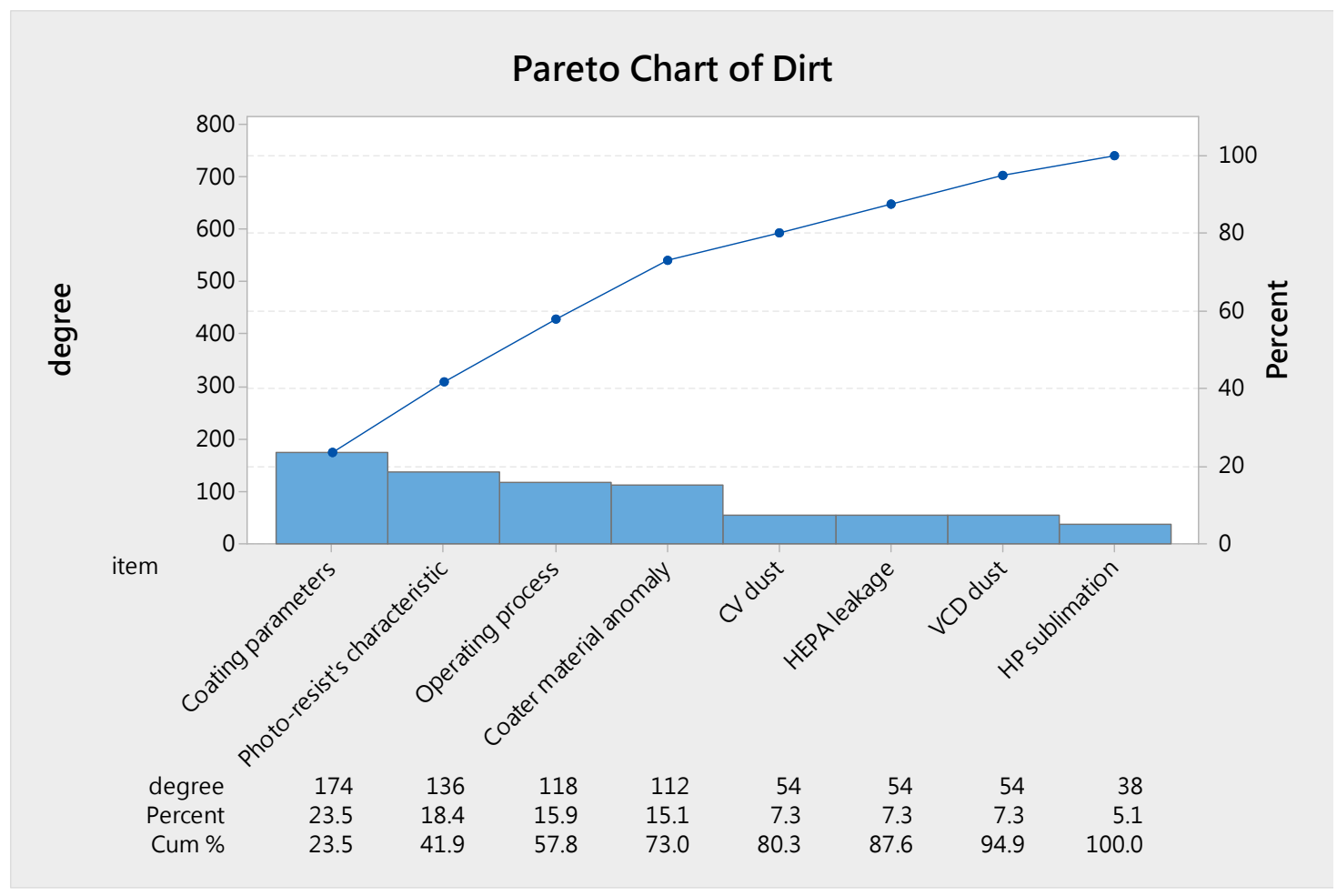

Figure 5. Pareto Chart (output from Minitab v14).

The team studies and assesses how risks are managed based on the various possibilities of risk analysis. The risks controlled by each process are analyzed by FMEA. It identifies the potential causes of contamination and the way of control during the processes. If the subsequent assessment has significant impact on the defect loss, it will be controlled in the project's end.

After identifying the process risk, we must first confirm the accuracy of the inspection personnel, so we need to analyze the measurement system. Since miscalculation or omission will have an impact 
on the yield of the product, and it should be identified first. We developed analytical plans as shown in Table 7, and the results are shown in Figure 6.

Table 7. Measurement system analysis (MSA) plan.

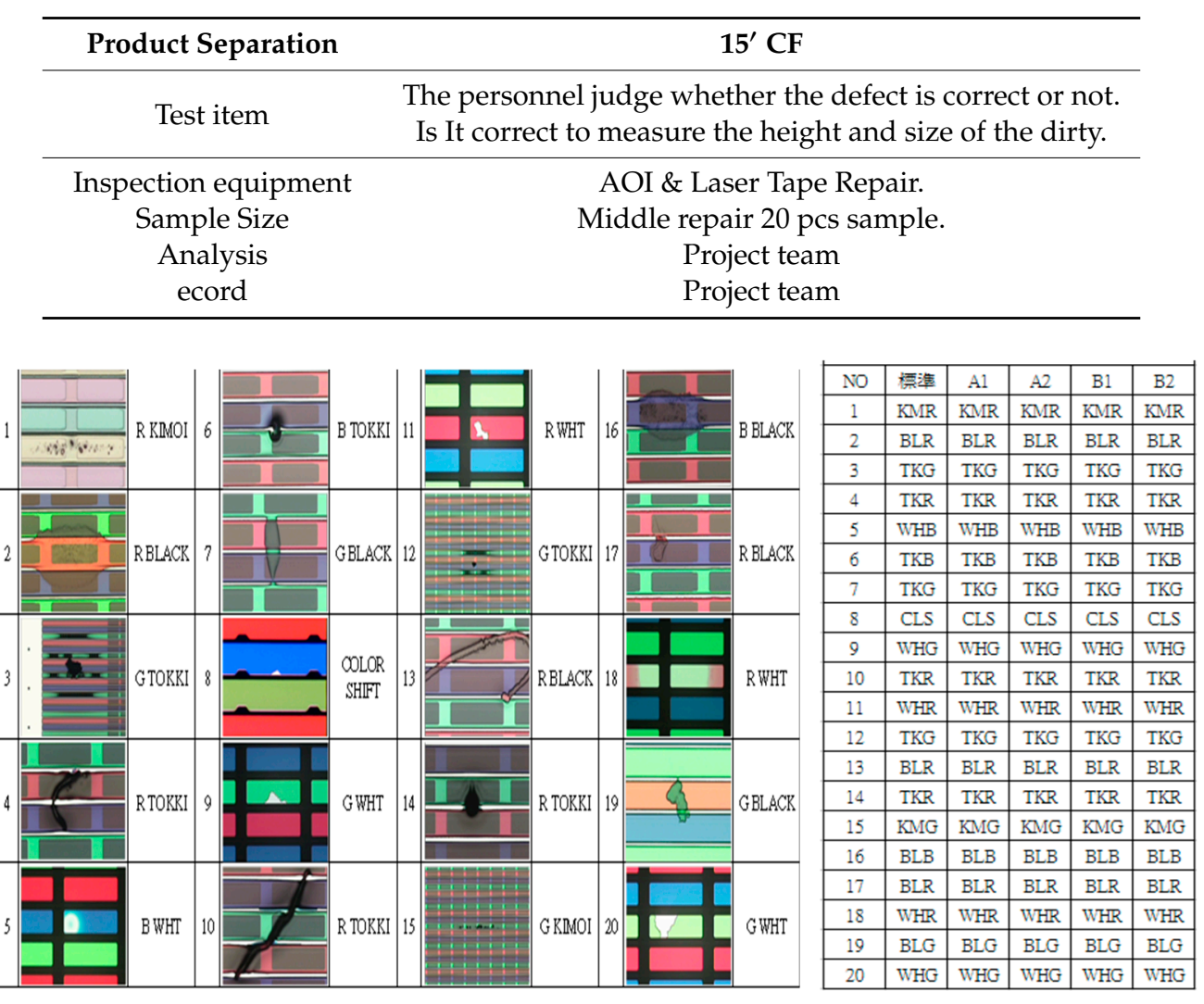

Figure 6. Sample selected for MSA and results of personnel measurement.

Table 7 represents the measurement system analysis test planning with the inspector. Figure 6 is a magnified photo of the sample selected in the test plan under an electron microscope. The inspector tests these test samples. The test results of these samples are recorded in the table below. In the table below, the second row indicates the standard test results for each test sample. These words represent the visual inspection defect codes in the case factory. The field below A1 represents the first test result of inspector " $\mathrm{A}$ " for each test sample. The field below A2 represents the second test result performed by inspector " $\mathrm{A}$ " for each test sample. The field below $\mathrm{B} 1$ represents the first test result performed by inspector "B" for each test sample. The field below B2 represents the second test result performed by inspector "B" for each test sample. The first inspection and the second inspection are separated by two weeks. We avoided inspectors who maintained stereotypes that affect the judgment of the test. We expect the inspectors to agree on the first and second inspection results. The inspectors, as well as the test standards, can have consistent test results. This represents the consistency of the measurement system.

The project team analyzed the above research results in statistical software and obtained the analysis results in Figure 7. The analysis chart on the left represents the consistency of the inspector's results at each test. The analysis chart on the right represents the consistency between the inspector and the test standard. The closer the analyzed data is to $100 \%$, the better the stability and correctness of the personnel test.

As shown in Figure 7, after confirming that the measurement was not controversial, it was reconfirmed that the proportion of foreign body residual in the processes was $0.17 \%$ to $0.42 \%$. Confirmation used hypothetical tests and statistical techniques, and the data collected during the period of identification and the define phase were not significantly different. 


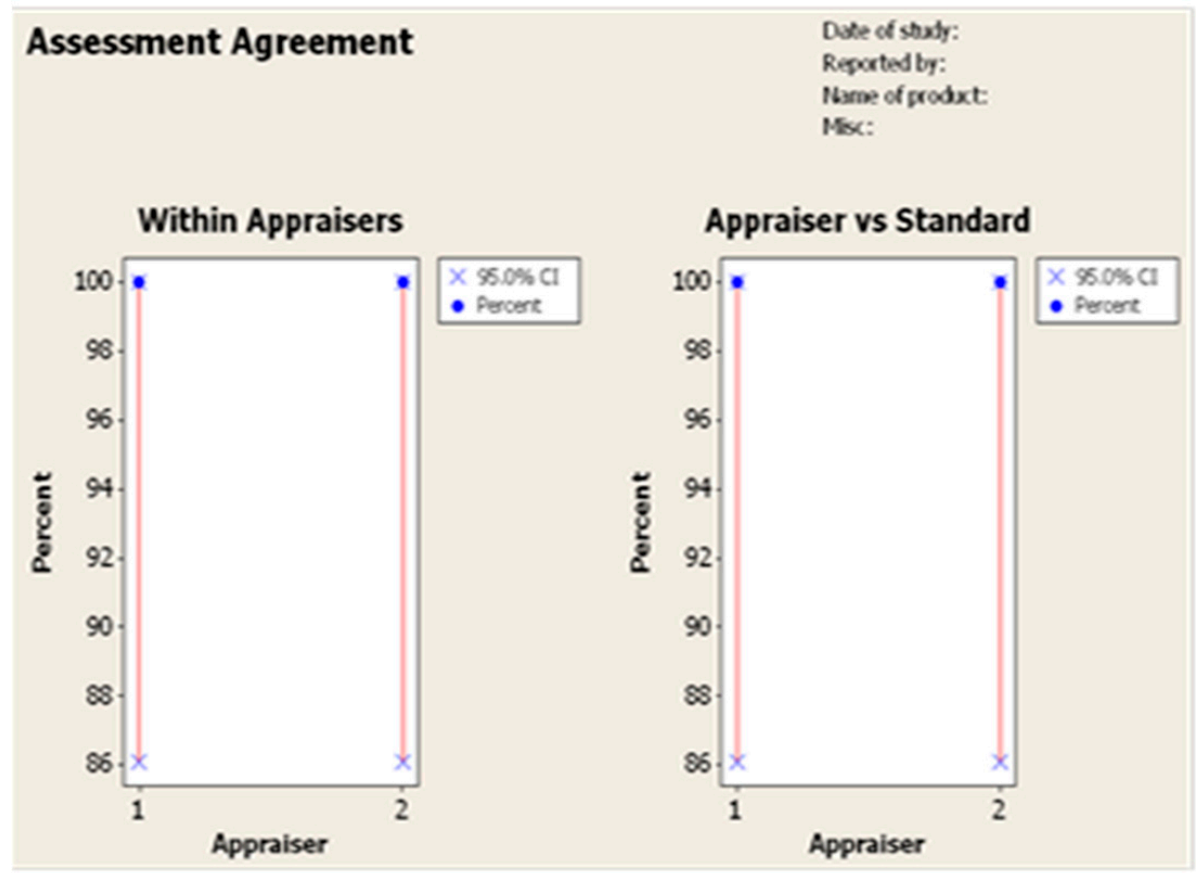

Figure 7. MSA with statistical software (output from Minitab v14).

\subsection{Analysis Phase}

During the Analyze phase, the project team began to work on the experimental design. The team hopes to identify the impact of processes control on the defect rate. The data collected during the Define and Measure phase are converted into experimental factors. There are twelve input factors (as shown in Table 8) and one output factor (the defect loss of dirt). The project team used the Design of Experiment method (DOE) to carry out the experimental project as shown in Table 8.

Table 8. DOE test's result.

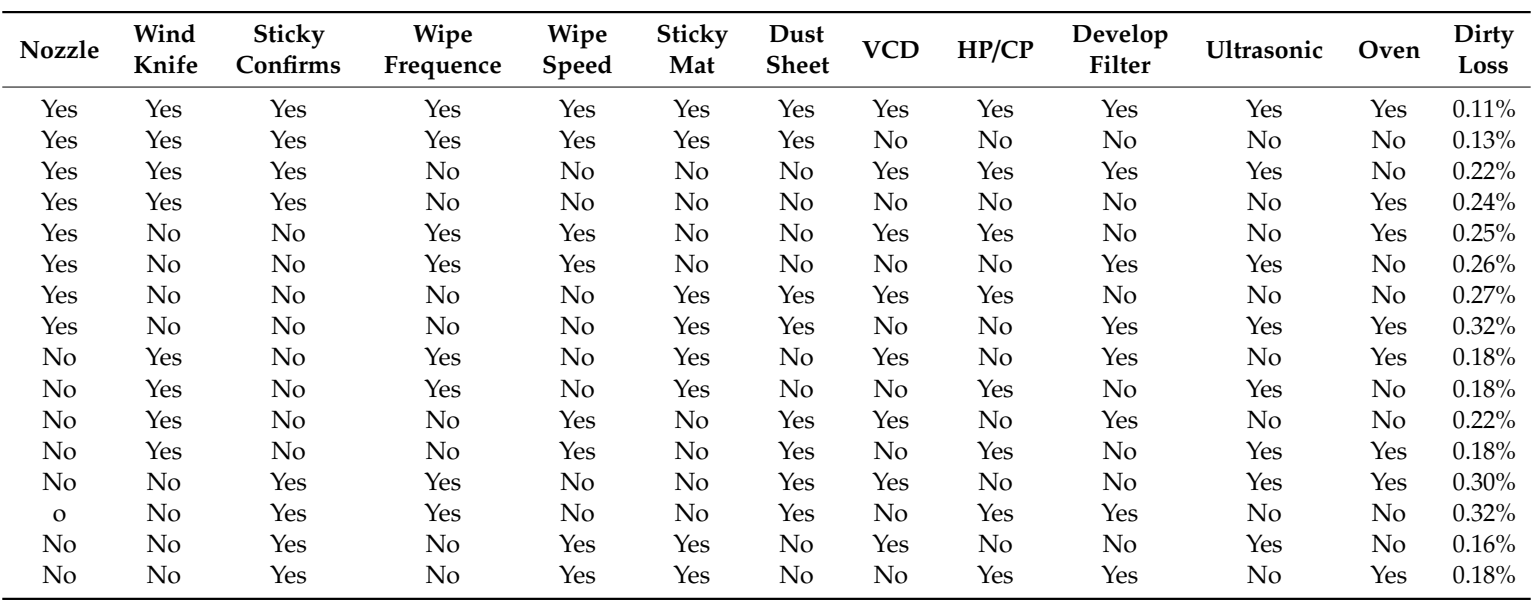

Independent variable description:

1. Nozzle: For use of the precleaner equipment, spray water with nozzle and wash glass substrate with brush. Experimental conditions-whether to open the nozzle swing to increase the sprinkler area. If the experiment level is "Yes", the nozzle will turn on the swing to increase the area of the sprinkler. If the level is "No", nozzle will turn on the swing.

2. Wind knife: The main function of the wind knife is to use high-pressure air to remove residual water on the glass after cleaning the glass. The test condition is to change the wind knife to a 45-60 
degree angle relative to the direction of the glass. If the experimental level is "Yes", the wind knife should be set at an angle of 45-60 degrees from the direction of travel of the glass. If the level is "No", the setting of the wind knife is perpendicular to the direction in which the glass travels.

3. Sticky confirms: When a die-coater is used for photo resistor coating, the scraper may have the problem of staining the photo resistor. The test condition is to verify the coating results every shift change (confirm with variation in film's thickness or color). If the experimental level is "Yes", the operator will test the coater when each class the shift is changed. Monitor product film thickness or chromaticity changes in coating. If the variation is too large, it is necessary to

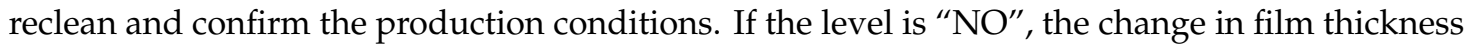
or chromaticity is maintained every time the production conditions are changed.

4. Wipe frequency: Continue with the above question. The test condition is to clean the dirt on the scraper in the coating every $30 \mathrm{~min}$ by the operator. If the experimental level is "Yes", the operator will clean the coater's scraper every $30 \mathrm{~min}$. Avoid curing the photo resistor on the scraper. If the level is "No", the operator will not increase this cleaning action.

5. Wipe speed: Continue with the above question. The test condition requires the operator to clean the scraper, and the cleaning speed must slow down and remove the photo resistor on the scraper. If the experimental level is " $Y$ ", the operator must use the special organic solvent for each cleaning and the cleaning should not be too fast; the cleaning time should be more than $30 \mathrm{~s}$. The residual photo resistor on the blade is completely removed. If the level is "No", the operator only needs to clean with $95 \%$ alcohol. And the wiping time needs to be within $30 \mathrm{~s}$.

6. Sticky mat: The test condition is that the substrate is a wet film, and the sticky mat is installed on the floor of the working site near the working area, e.g., coating machine. If the experimental level is "Yes", the sticky mat is placed on the floor to prevent particle floating generation when the person is moving. If the level is "No", the floor maintains a perforated floor.

7. Dust sleeve: In order to prevent the equipment from dusting, the test condition is to set up the dust sleeve or adhesive paper on the machine to reduce the problem of dirt in the equipment (e.g., dusting on the arm of robot). If the experimental level is "Yes", put a dust sleeve or sticky paper that is easy to dust on the equipment. If the level is "No", it does not need to put on a dust sleeve and sticky paper.

8. VCD (vacuum dry): Test conditions for each exchange product change, the site required to clean the VCD equipment, and the High Efficiency Particulate Air (HEPA) on the ceiling of the area, because there is $\sim 70 \%$ or greater by proportion of chemical solvents in the photo resistor. Therefore, the photo resistor needs to be extracted and dissociated by a chemical solvent after coating. The goal is to improve the stability of the process. This part is handled by the VCD. If the experimental level is "Yes", the VCD will be cleaned each time the production conditions are changed, and the HEPA above the VCD will be cleaned. If the level is "No", no cleaning is required when changing the production conditions. It only needs to be cleaned and maintained according to the original equipment maintenance frequency.

9. HP/CP: Test conditions for each exchange product line change, the site required to clean $\mathrm{HP} / \mathrm{CP}$ equipment and the High Efficiency Particulate Air (HEPA) on the ceiling of the area. The photo resistor is coating on the glass, and the photo resistor exhibits a liquid state. It is easy to shift due to the movement of the glass. Therefore, it is necessary to cure through HP/CP. HP mainly heats the coated glass at a high temperature to fix the photo resistor. The temperature of the glass is cooled down through the $\mathrm{CP}$ to return to normal temperature. If the experimental level is "Yes", the $\mathrm{HP} / \mathrm{CP}$ is cleaned each time the production conditions are changed. And clean the HEPA above the HP/CP. If the level is "No", there is no need to clean and maintain when changing production conditions. Just keep the general cleaning cycle.

10. Develop filter: In the wet development, the test condition is to add a secondary filter core to the pure water filter center. After the photo resistor is exposed, a chemical change is produced by the Developer. The developer during Development is recycled. Originally filtered through 
a filter before use. If the experimental level is "Yes", a filter with a smaller aperture will be added. The impurities in the developer are filtered. If the level is "No", keep a filter.

11. Ultrasonic: Test conditions for glass cleaning, open ultrasonic cleaning in the cleaner. In the current wet equipment, both the precleaner and developing machine are cleaned with pure water. And the Ultrasonic cleaning function can be turned on during cleaning. It can clean particles on the glass. If the experiment level is "Yes", the Ultrasonic cleaning function is turned on. If the level is "No", this feature is not used.

12. Oven: Test conditions for each exchange product line change, as well as the site required to clean oven equipment and the High Efficiency Particulate Air (HEPA) on the ceiling of the area. The front HP/CP device only slightly fixes the photo resistor quickly at high temperatures. Oven equipment will be baked at high temperatures. Oven will be baked at high temperatures for a long-time baking. Therefore, it is easy to have many problems of aging, rust and dust. The experimental level is "Yes" and will require cleaning of Oven each time the production conditions change. However, if the level is "No", the cleaning frequency of the Oven device maintains the original cleaning frequency (monthly).

This study was designed with statistical software (Minitab). Each column in Table 8 represents a set of production conditions. The case is set with the production conditions as shown in Table 8. Each set of experiments will use two-hundred large plates of glass as test samples. The case is provided to the customer for visual inspection, and the customer provides "dirty" (or contaminant) yield data placed in the last row of Table 8. The results of these experiments were analyzed using software. The team analyzed the results with statistical software as shown in Figure 8 \& Table 9. It is salience conditions with the DOE's result include a wind knife, sticky confirm, wipe speed, and sticky mat.

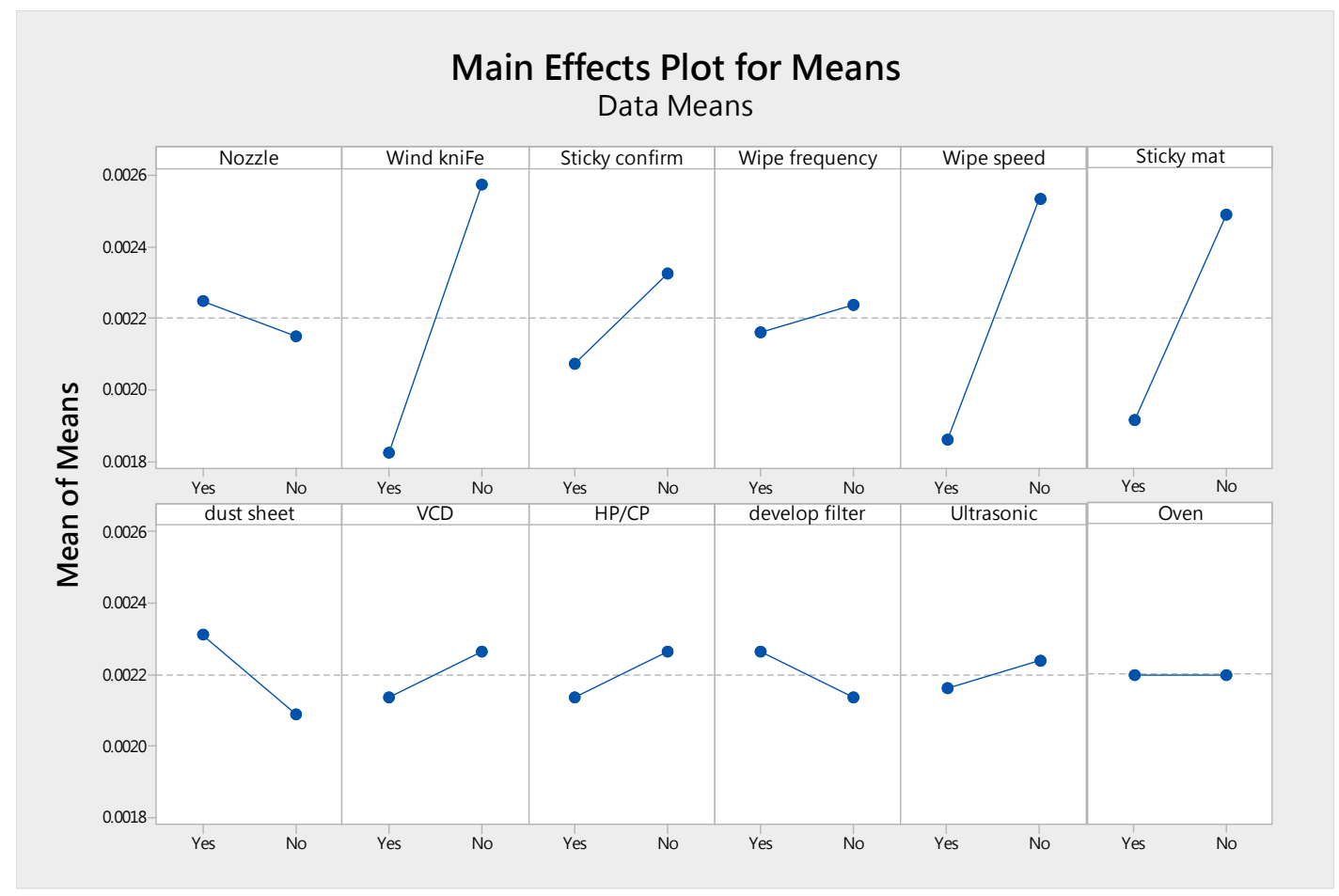

Figure 8. Main effects plot for means (output from Minitab v14). 
Table 9. Analysis results of DOE (output from Minitab v14).

\begin{tabular}{cccccc}
\hline Analysis of Variance & \multicolumn{5}{c}{} \\
\hline Source & DF & Adj SS & Adj MS & F-Value & P-Value \\
\hline Nozzle & 1 & 0.000000 & 0.000000 & 1.50 & 0.308 \\
Wind knife & 1 & 0.000002 & 0.000002 & 84.37 & 0.003 \\
Sticky confirms & 1 & 0.000000 & 0.000000 & 9.37 & 0.055 \\
Wipe frequency & 1 & 0.000000 & 0.000000 & 0.84 & 0.426 \\
Wipe speed & 1 & 0.000002 & 0.000002 & 68.34 & 0.004 \\
Sticky mat & 1 & 0.000001 & 0.000001 & 49.59 & 0.006 \\
dust sheet & 1 & 0.000000 & 0.000000 & 7.59 & 0.07 \\
VCD & 1 & 0.000000 & 0.000000 & 2.34 & 0.223 \\
HP / CP & 1 & 0.000000 & 0.000000 & 2.34 & 0.223 \\
develop filter & 1 & 0.000000 & 0.000000 & 2.34 & 0.223 \\
Ultrasonic & 1 & 0.000000 & 0.000000 & 0.84 & 0.426 \\
Oven & 1 & 0.000000 & 0.000000 & 0.00 & 1.000 \\
Error & 3 & 0.000000 & 0.000000 & & \\
Total & 15 & 0.000006 & & & \\
\hline Model Summary & & & & & \\
\hline S & R-sq & R-sq(adj) & R-sq(pred) & & \\
0.0001633 & $98.71 \%$ & $93.55 \%$ & $63.30 \%$ & &
\end{tabular}

\subsection{Improve Phase}

After the experimental design was verified, the project team began the tests. The test conditions were as follows.

1. Changing the angle of the wind knife to 45 degrees angle with the flow direction of the glass substrate.

2. The change of color or film thickness is controlled, and the change of unit distance is abnormal according to the product requirement.

3. The control wiping speed must not be too fast and the photo resistor residue attached to the scraper should be completely removed.

4. Set sticky mat on the floor of scraper coating equipment.

Start with mass production (lot: M7807U10) improvement identification (R7807U70 is not controlled product lot), the difference before and after improvement is shown in Figure 9.

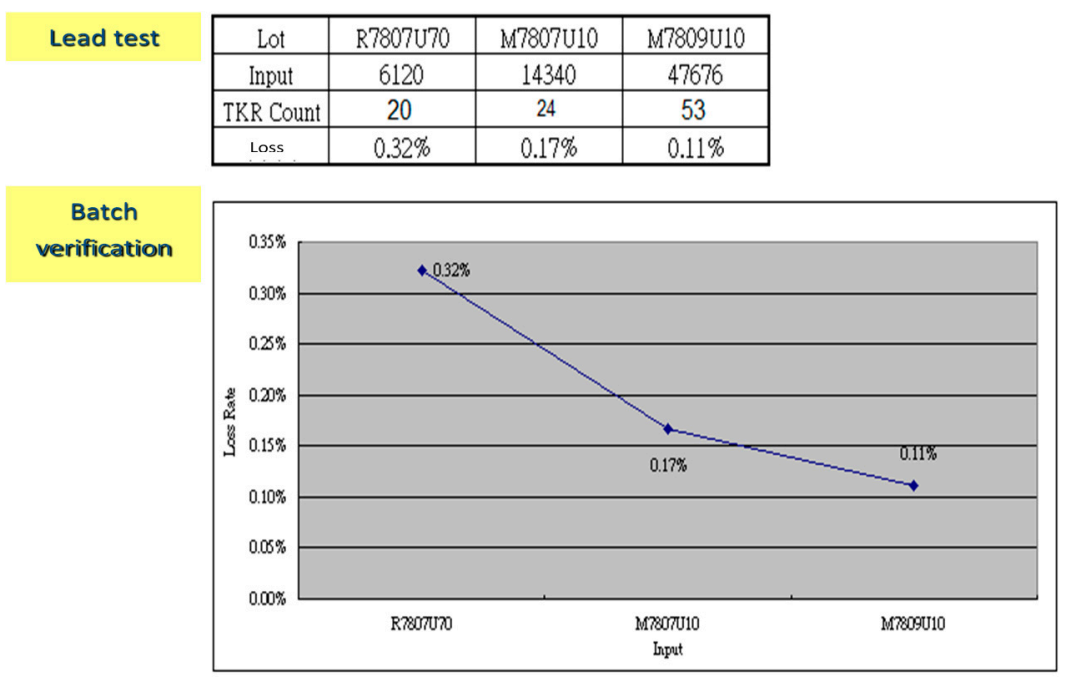

Figure 9. Results of the pretest for improvement of dirt defect. 
Analyze the impact of improvement on rework-product before and after improvement. Analyze the proportion of rework and the proportion of products that need to be scrapped as shown in Table 10. Through implementation improvement, effectively reduce the number of rework-product and the number of abnormal scrap (Loss\%). After the project team validated the effectiveness of the improvements, the strategy was implemented to other products of the company, and the results were also significant, as shown in Figure 10. In the 19" product's yield, which reduce the proportion of dirty from $3.12 \%$ to $0.41 \%$. Following the improvement of the photo resistor in November, the proportion of dirt residue was controlled within $0.18 \%$ of the project target. So, the project enters the control phase.

Table 10. The quantity of rework and dirt per month.

\begin{tabular}{ccccc}
\hline Classify & Month & Quantity & TKR & Loss \% \\
\hline \multirow{2}{*}{ Before } & 4 & 35229 & 1559 & $0.37 \%$ \\
& 5 & 21669 & 1108 & $0.43 \%$ \\
\hline \multirow{2}{*}{ Test } & 6 & 12865 & 620 & $0.40 \%$ \\
& 7 & 10586 & 286 & $0.23 \%$ \\
\hline \multirow{2}{*}{ After } & 8 & 18292 & 339 & $0.15 \%$ \\
& 9 & 18398 & 299 & $0.14 \%$ \\
\hline
\end{tabular}

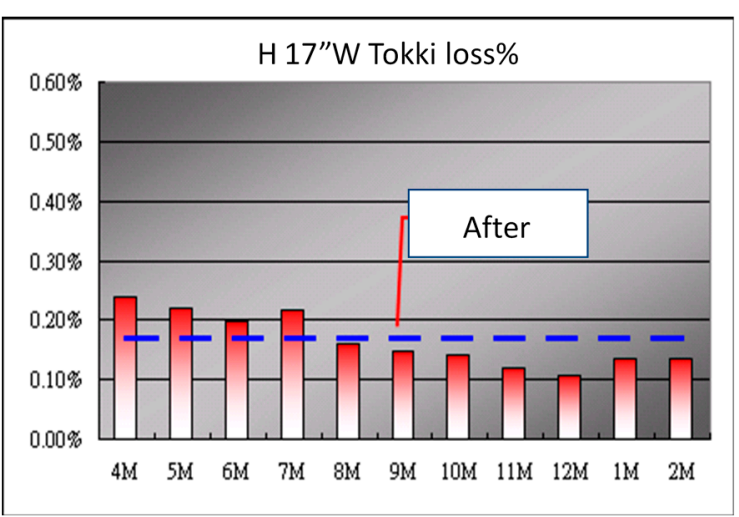

(a)

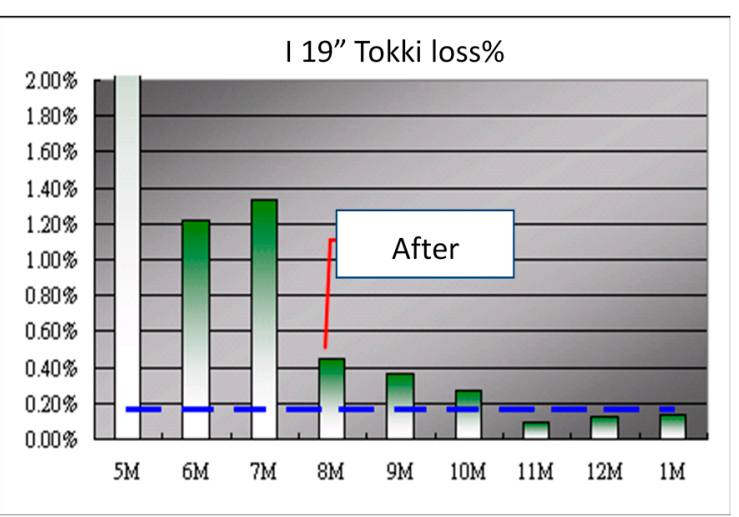

(b)

Figure 10. The yield of defect loss about Tokki (dirty) (a) 17" add Width product (b) 19" product. (In b, the in-plant improvement plan was completed in August. The reason for the failure to meet the target was that the improvement of the photo resistor supplier was completed in October, so the improvement target was achieved in November.)

\subsection{Control Phase}

After the team completes the improved validation, the technical report is handed over to the processes team. Add or modify the obtained results into the current standard operating procedures (SOPs). In order to ensure that improvement measures are implemented in actual production, the team commissioned IPQC engineers to conduct processes audits for three months, until they have made sure the operators have formed the working habit for improving the countermeasures, and then relax the processes audit frequency. The team improved the processes, the exception handling processes recommendations, and the actual work in the current site, including the following:

1. Improvement of photo resistor solubility: it is suggested that photo resistor materials are verified by introducing lip test with supplier.

2. Wind knife setting of the cleaning line: the angle of the wind knife and the direction of the glass travel are clamped at 45 degrees angle.

3. Wipe speed of the scraper and formulates in the SOP.

4. Control chromaticity or thickness of film: it is recommended that be included in the control plan. 
5. Sticky mat: set sticky mat on the floor of the die-coater.

\section{Conclusions}

In this study, the quality of the case is optimized by combining the improvement of the Lean Six Sigma. Through the Lean Six Sigma, we defined each phase's mission, which helped to pull the project. Through the project, the defect rate is reduced to $0.13 \%$, as shown in Figure 11, the project has been significantly improved. The total number of experiments was reduced from $4096(=212)$ to 16 by using the DOE method. Reduce the amount of time and costs that companies need to spend.

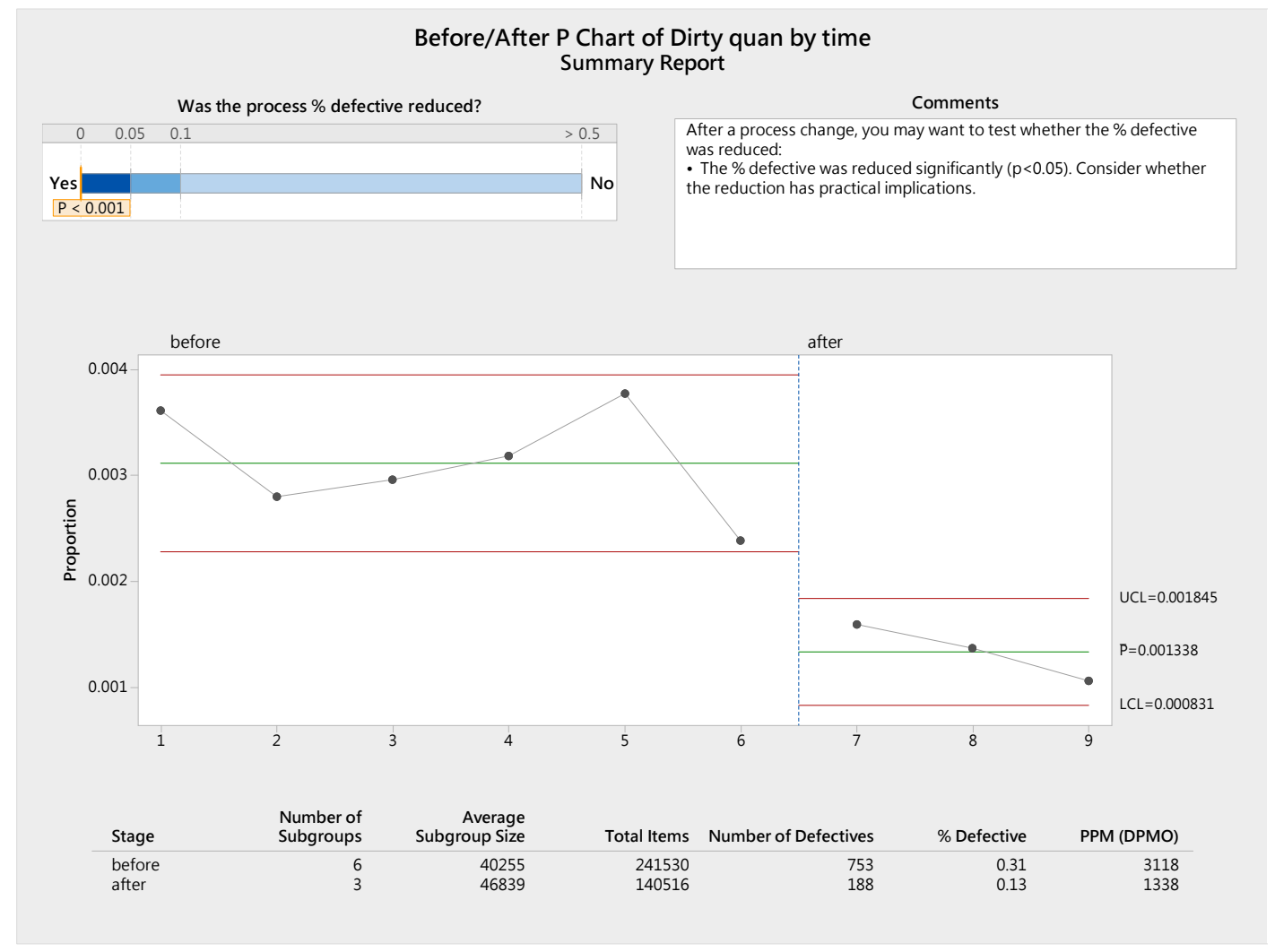

Figure 11. Before/after P chart of dirt (output from Minitab v14).

The defect rate at the end of the project has met the customer requirements (less than $0.20 \%$ ), so was applied until the end of the project. Compared with the historical data of the case, the improved single product yield estimate reduces the nonperforming loss (including rework, scrap, and derivative compensation) of at least 0.6 million (USD) for the case company. The project reduces the defect rate of products and reduces the number of products that need to be repaired. Indirectly reduce the number of times the process is forced to stop; because of the smooth process and the increased equipment turnover, the potential benefits are even more difficult to estimate.

In addition, in the operation management of the enterprise, the management method of LSS defines the processes of each stages in detail. Therefore, in the management of the case, there are the many other cases in the company in which the project objectives can be achieved in the processes of improvement. For example, through MSA, it is found that the variation is not caused by the product processes, but is caused by the instability of the measurement system. Using measure system analysis can effectively avoid the waste of enterprise resources caused by wrong information. For example, there is no problem in the production system, because the measurement is judged to be wrong, resulting in unnecessary waste of the stoppage, process adjustment, and other resources at the production site.

Again, through the study of actual cases, the complementary effects produced by the combination of Lean Production and Six Sigma confirmed. The case's company has two years of continuous 
improvement of statistics, including 3 to $7 \%$ of issue cases that can be closed through the processes and confirmation (including Define or Measure phases). Help for the organization is not only quickly close the issue, and also to effectively apply the enterprise resources to the correct and really need to invest in the project. In the analysis and improve phase, through the scientific and statistical methods, the experimental tests are more effective than the previous trial and error methods. Using Design of Experiments to accelerate, shorten the test time, and effectively reduce the number of experiments invested, greatly reduce the cost of the experiment and obtain more complete analysis data and results.

For the enterprise, the processes of continuous improvement require full investment, including the commitment from the executive to the definition and selection of project factors by the grassroots personnel on the spot, which can help the cohesiveness of the enterprise. In many past studies, management input is often seen as one of the key factors in the success of the project. Relatively represents the investment of enterprise resources. In addition to leadership support, related training activities are also of particular importance. It is related to the correctness and proficiency of the relevant personnel for the use of the tool. This is also the success factor for companies to derive continuous improvement.

Author Contributions: Conceptualization, C.-N.W. and P.-C.C.; Methodology, P.-C.C.; Software, P.-C.C.; Validation, I.-F.C.; Formal Analysis, P.-C.C.; Investigation, I.-F.C.; Resources, P.-C.C.; Data Curation, P.-C.C.; Writing-Original Draft Preparation, I.-F.C.; Writing-Review and Editing, C.-N.W. and P.-C.C., Y.-F.H.; problem solving and modified the revised version, Y.-F.H.; research budget supported, Y.-F.H.

Funding: This research received no external funding.

Conflicts of Interest: The authors declare no conflict of interest.

\section{References}

1. Mills, C.; Carnell, M.; Wheat, B. Leaning into Six Sigma: The Path to Integration of Lean Enterprise and Six Sigma; McGraw-Hill Education: New York, NY, USA, 2001.

2. Womack, J.; Jones, D. Lean Thinking: Banish Waste and Create Wealth in Your Corporation; Simon \& Schuster: New York, NY, USA, 2003.

3. George, M. The Lean Six Sigma Pocket Tool Book: A Quick Reference Guide to 100 Tools for Improving Quality and Speed; McGraw-Hill Education: New York, NY, USA, 2004.

4. Wheat, B.; Mills, C.; Carnell, M. Learning into Six Sigma: A Parable of the Journey to Six Sigma and a Lean Enterprise; McGraw-Hill Education: New York, NY, USA, 2001.

5. Krafcik, J.F. Triumph of the lean production system. Sloan Manag. Rev. 1988, 30, 41-52.

6. Kwak, Y.H.; Anbari, F.T. Benefits, obstacles, and future of six sigma approach. Technovation 2006, 26, 708-715. [CrossRef]

7. Holweg, M. The genealogy of lean production. J. Oper. Manag. 2007, 25, 420-437. [CrossRef]

8. De Feo, J.A.; Barnard, W. JURAN Institute's Six Sigma Breakthrough and Beyond-Quality Performance Breakthrough Methods; McGraw-Hill Education: New York, NY, USA, 2004.

9. Womack, J.; Roos, D.; Jones, D.T. Lean Thinking—Banish Waste and Create Wealth in Your Corporation; Simon \& Schuster: New York, NY, USA, 1996.

10. Furterer, S. Lean Six Sigma in Service: Applications and Case Studies; CRC Press Taylor \& Francis Group: Boca Raton, FL, USA, 2009.

11. Wedgwood, I. Lean Sigma-A Practitioner's Guide; Prentice Hall: Upper Saddle River, NJ, USA, 2006.

12. Chen, K.S.; Wang, C.H.; Chen, H.T. A MAIC approach to TFT-LCD panel quality improvement. Microelectron. Reliab. 2006, 46, 1189-1198. [CrossRef]

13. Chen, M.N.; Lyu, J.J. A Lean Six-Sigma approach to touch panel quality improvement. Prod. Plan. Control 2009, 20, 445-454. [CrossRef]

14. Caligiana, G.; Liverani, A.; Francia, D.; Frizziero, L.; Donnici, G. Integrating QFD and TRIZ for innovative design. J. Adv. Mech. Des. 2017, 11, 1-15. [CrossRef]

15. Francia, D.; Caligiana, G.; Liverani, A.; Frizziero, L.; Donnici, G. PrinterCAD: A QFD and TRIZ integrated design solution for large size open moulding manufacturing. Int. J. Interact. Des. Manuf. 2018, 12, 81-94. [CrossRef] 
16. Frizziero, L.; Francia, D.; Donnici, G.; Liverani, A.; Caligiana, G. Sustainable design of open molds with QFD and TRIZ combination. J. Ind. Prod. Eng. 2018, 35, 21-31. [CrossRef]

17. Takatsuji, H.; Arai, T. Pinholes in Al thin films: Their effects on TFT characteristics and a taguchi method analysis of their origins. Vacuum 2000, 59, 606-613. [CrossRef]

18. Chiang, Y.M.; Hsieh, H.H. The use of the Taguchi method with grey relational analysis to optimize the thin-film sputtering process with multiple quality characteristic in color filter manufacturing. Comput. Ind. Eng. 2009, 56, 648-661. [CrossRef]

19. Kornfeld, B.J.; Kara, S. Project portfolio selection in continuous improvement. Int. J. Oper. Prod. Manag. 2011, 31, 1071-1088. [CrossRef]

20. Cima, R.R.; Brown, M.J.; Hebl, J.R.; Moore, R.; Rogers, J.C.; Kollengode, A.; Amstutz, G.J.; Weisbrod, C.A.; Narr, B.J.; Deschamps, C.; et al. Use of lean and six sigma methodology to improve operating room efficiency in a high-volume tertiary-care academic medical center. J. Am. Coll. Surg. 2011, 213, 83-92. [CrossRef] [PubMed]

21. Dahlgaard, J.J. Lean production, six sigma quality, TQM and company culture. TQM Mag. 2006, 18, $263-281$. [CrossRef]

22. Realyvásquez-Vargas, A.; Arredondo-Soto, K.C.; Carrillo-Gutiérrez, T.; Ravelo, G. Applying the Plan-Do-Check-Act (PDCA) Cycle to Reduce the Defects in the Manufacturing Industry. A Case Study. Appl. Sci. 2018, 8, 2181. [CrossRef]

23. Zheng, Y.; Gao, P.; Xiao, Z.; Zhou, J.; Duan, J.; Chen, B. Improving the Lot Fabrication Stability and Performance of Silica Optical Films during PECVD. Appl. Sci. 2019, 9, 785. [CrossRef]

(C) 2019 by the authors. Licensee MDPI, Basel, Switzerland. This article is an open access article distributed under the terms and conditions of the Creative Commons Attribution (CC BY) license (http://creativecommons.org/licenses/by/4.0/). 